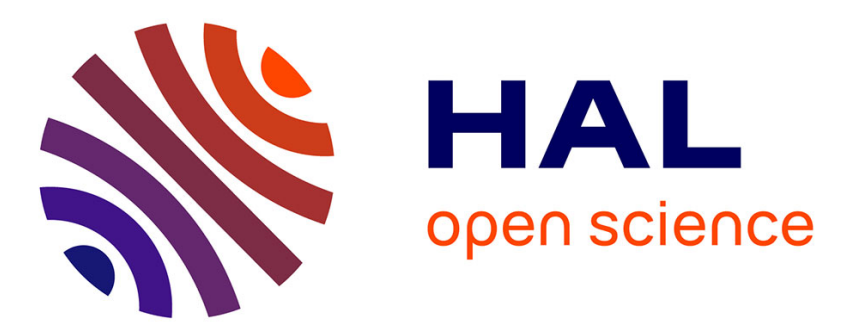

\title{
Influence of the supersaturation on Si diffusion and growth of Si nanoparticles in silcion-rich silica
}

M. Roussel, Etienne Talbot, Philippe Pareige, Fabrice Gourbilleau

\section{To cite this version:}

M. Roussel, Etienne Talbot, Philippe Pareige, Fabrice Gourbilleau. Influence of the supersaturation on Si diffusion and growth of Si nanoparticles in silcion-rich silica. Journal of Applied Physics, 2013, 113, pp.063519. 10.1063/1.4792218 . hal-00788699

\section{HAL Id: hal-00788699 \\ https://hal.science/hal-00788699}

Submitted on 16 Jan 2019

HAL is a multi-disciplinary open access archive for the deposit and dissemination of scientific research documents, whether they are published or not. The documents may come from teaching and research institutions in France or abroad, or from public or private research centers.
L'archive ouverte pluridisciplinaire HAL, est destinée au dépôt et à la diffusion de documents scientifiques de niveau recherche, publiés ou non, émanant des établissements d'enseignement et de recherche français ou étrangers, des laboratoires publics ou privés. 


\section{AIP Appilied Physics}

\section{Influence of the supersaturation on Si diffusion and growth of $\mathrm{Si}$ nanoparticles in silicon-rich silica}

M. Roussel, E. Talbot, P. Pareige, and F. Gourbilleau

Citation: J. Appl. Phys. 113, 063519 (2013); doi: 10.1063/1.4792218

View online: http://dx.doi.org/10.1063/1.4792218

View Table of Contents: http://jap.aip.org/resource/1/JAPIAU/v113/i6

Published by the American Institute of Physics.

\section{Related Articles}

Comb-drive micro-electro-mechanical systems oscillators for low temperature experiments Rev. Sci. Instrum. 84, 025003 (2013)

Influence of the embedding matrix on optical properties of Ge nanocrystals-based nanocomposite J. Appl. Phys. 113, 053512 (2013)

Fabrication of Bi2Te3 nanowire arrays and thermal conductivity measurement by $3 \omega$-scanning thermal microscopy

J. Appl. Phys. 113, 054308 (2013)

Controlled route to the fabrication of carbon and boron nitride nanoscrolls: A molecular dynamics investigation J. Appl. Phys. 113, 054306 (2013)

Electrodynamic control of the nanofiber alignment during electrospinning Appl. Phys. Lett. 102, 053111 (2013)

\section{Additional information on J. Appl. Phys.}

Journal Homepage: http://jap.aip.org/

Journal Information: http://jap.aip.org/about/about_the_journal

Top downloads: http://jap.aip.org/features/most_downloaded

Information for Authors: http://jap.aip.org/authors

\section{ADVERTISEMENT}

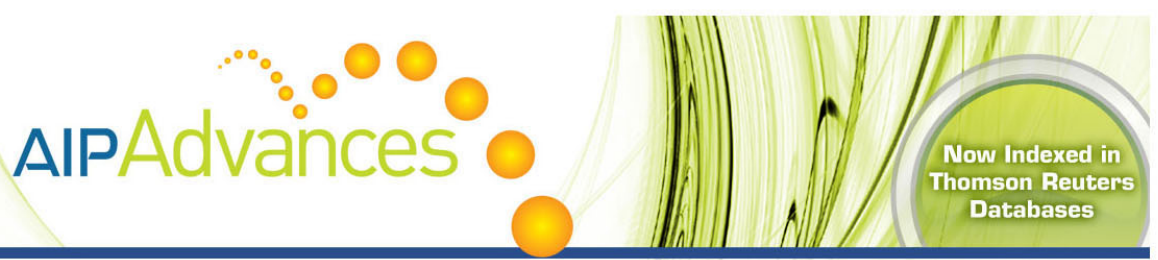

\section{Explore AIP's open access journal: - Rapid publication \\ - Article-level metrics \\ - Post-publication rating and commenting}




\title{
Influence of the supersaturation on Si diffusion and growth of $\mathrm{Si}$ nanoparticles in silicon-rich silica
}

\author{
M. Roussel, ${ }^{1}$ E. Talbot, ${ }^{1, a)}$ P. Pareige, ${ }^{1}$ and F. Gourbilleau ${ }^{2}$ \\ ${ }^{1}$ Groupe de Physique des Matériaux (GPM) UMR 6634, Normandie Université, Université et INSA de \\ Rouen-CNRS, Av. de l'Université, BP 12, 76801 Saint Etienne du Rouvray, France \\ ${ }^{2}$ Centre de Recherche sur les Ions, les Matériaux et la Photonique (CIMAP), CEA/CNRS/ENSICAEN/UCBN, \\ 6 Bd. Maréchal Juin, 14050 Caen Cedex 4, France
}

(Received 19 September 2012; accepted 30 January 2013; published online 14 February 2013)

\begin{abstract}
$\mathrm{SiO}_{X} / \mathrm{SiO}_{2}$ multilayers have been prepared using magnetron sputtering and annealed in order to induce the growth of Si nanoparticles in Si-rich sublayers. This sample has undergone several successive annealing treatments and has been analyzed using a laser-assisted tomographic atom probe. This allows the phase separation between $\mathrm{Si}$ and $\mathrm{SiO}_{2}$ and the growth process to be studied at the atomic scale as a function of annealing temperature. Si diffusion coefficient is estimated from the accurate measurement of matrix composition and Si particle size. We demonstrate that the diffusion coefficient in $\mathrm{SiO}_{X}$ is supersaturation dependent, leading to a decrease in silicon particle growth kinetics during annealing. In addition, we use our measurements to predict the critical thickness for efficient $\mathrm{SiO}_{2}$ diffusion barriers. (C) 2013 American Institute of Physics.
\end{abstract}

[http://dx.doi.org/10.1063/1.4792218]

\section{INTRODUCTION}

The discovery of photoluminescence (PL) of porous silicon by Canham ${ }^{1}$ has demonstrated that silicon nanostructures are very promising materials for photonic applications. Thus, silicon nanoparticles (Si-nps) embedded in a dielectric matrix like $\mathrm{SiO}_{2}$ have attracted major interest during the past few years. These materials exhibit quantum confinement effect in Si-nps and are fully compatible with silicon nanotechnology. Typical application fields concern the 3rd generation of solar cells, ${ }^{2}$ waveguide amplifiers ${ }^{3}$ (if samples are doped with rare-earth atoms), and new memory devices based on carrier storage. ${ }^{4}$ One of the major challenges for such applications is to control accurately structural characteristics of Si-nps, such as size distribution and density. For instance, tunable photoluminescent systems have been realized by accurately controlling the size distribution of Sinps. ${ }^{5}$ In such systems, optical properties also strongly depend on the nature of the interface between the Si-nps and the silica matrix. ${ }^{6}$ In addition, in the case of electroluminescent devices or nanomemories, the quality of the dielectric matrix is of prime interest. A suboxide matrix can lead to undesirable charge trapping effects and, thereby, lead to the deterioration of electroluminescent or charge storage properties. ${ }^{7-9}$ All these characteristics are determined during the formation and growth of Si-nps. Usually, Si-nps are obtained by using silicon-rich silicon oxide $\left(\mathrm{SiO}_{X}\right)$ prepared by deposition techniques (PECVD ${ }^{10}{ }^{10}$ magnetron sputtering ${ }^{2}$ ) or silicon implantation in silica. ${ }^{11} \mathrm{SiO}_{X}$ is then annealed in order to induce the phase separation between $\mathrm{Si}$ and $\mathrm{SiO}_{2}$, as predicted by the binary Si-O phase diagram. ${ }^{12}$ Controlling the size of Si-nps is commonly achieved by preparing $\mathrm{SiO}_{X} / \mathrm{SiO}_{2}$ multilayers (MLs). ${ }^{13}$ During phase separation, $\mathrm{SiO}_{2}$ sublayers act as diffusion barriers and limit the growth of Si-nps to the thickness

${ }^{a)}$ Electronic mail: etienne.talbot@univ-rouen.fr. of $\mathrm{SiO}_{X}$ sublayers. Hence, it is essential to measure the diffusion coefficient in $\mathrm{SiO}_{X}$ and $\mathrm{SiO}_{2}$ accurately in order to anticipate growth kinetics in Si-np based devices. Various studies have focused on the diffusion mechanism of $\mathrm{Si}$ in $\mathrm{SiO}_{2}{ }^{14}$ by means of various techniques such as SIMS, ${ }^{15}$ TEM, ${ }^{16}$ and RBS. ${ }^{17}$ Unfortunately, these studies provide a wide range of diffusion coefficient values, and it appears that $\mathrm{Si}$ diffusion mechanism in $\mathrm{SiO}_{2}$ is still unclear. In this work, we have studied the structural and chemical properties of annealed $\mathrm{SiO}_{X} / \mathrm{SiO}_{2}$ multilayers using atom probe tomography (APT). To our knowledge, APT appears to be the only technique that is able to provide a full description of these materials. Indeed, APT overcomes most of the limitations encountered by conventional techniques by providing a 3D chemical map of the sample at the atomic scale. For instance, APT is able to evidence all Si-nps regardless of their structure (crystalline or amorphous) unlike HRTEM. In addition, it provides a 3D reconstruction of the sample, which is, in the case of multilayered structures, much more convenient than planar projections provided by microscopy techniques. Furthermore, it permits to measure directly the composition of the surrounding oxide, which is, usually, only extrapolated when using EFTEM. Finally, it is a very sensitive technique, which is able to identify the smallest particles (smaller than $1 \mathrm{~nm}$ diameter). The purpose of this study is to investigate the influence of annealing treatments on the growth of Si-nps and to determine the diffusion coefficient of $\mathrm{Si}$ in $\mathrm{SiO}_{X}$ and $\mathrm{SiO}_{2}$.

\section{EXPERIMENTAL}

A set of $\mathrm{SiO}_{X} / \mathrm{SiO}_{2}$ multilayer was deposited on [100] oriented silicon wafer using the reactive magnetron sputtering technique. $\mathrm{SiO}_{2}$ sublayers were deposited using a pure silica target under $\mathrm{Ar}$ plasma while $\mathrm{SiO}_{X}$ ones were fabricated by sputtering the silica target under $50 \% \mathrm{Ar}+50 \% \mathrm{H}_{2}$ 
mixture plasma. During this process, $\mathrm{H}_{2}$ reduces oxygen and a silicon-rich layer (containing approximately 50 at. \%) is deposited. The ML was grown at $650^{\circ} \mathrm{C}$ with a power density of $1.3 \mathrm{~W} \cdot \mathrm{cm}^{-2}$. The sputtering time permits to tune $\mathrm{SiO}_{X}$ and $\mathrm{SiO}_{2}$ sublayer thicknesses, which have been measured by HRTEM to be $4 \mathrm{~nm}$. More details about the deposition process have been given by Ternon et al. in a previous paper. ${ }^{13}$ This $\mathrm{ML}$ is then annealed at $900{ }^{\circ} \mathrm{C}$ for $1 \mathrm{~h}$ under $\mathrm{N}_{2}$ flow, which is efficient enough to initiate phase separation in such systems. This state will be referred as the reference state (a) thereafter. In order to study the phase separation and the Si-np growth, additional annealing treatments have been applied to the same sample $\left(1 \mathrm{~h}\right.$ at $900^{\circ} \mathrm{C}+1 \mathrm{~h}$ at $1000^{\circ} \mathrm{C}$ (b), $1 \mathrm{~h}$ at $900^{\circ} \mathrm{C}+1 \mathrm{~h}$ at $1100^{\circ} \mathrm{C}(\mathrm{c})$ and $1 \mathrm{~h}$ at $900^{\circ} \mathrm{C}+2 \mathrm{~h}$ at $\left.1100^{\circ} \mathrm{C}(\mathrm{d})\right)$.

After each annealing treatment, the MLs have been analyzed by laser assisted wide angle tomographic atom probe (LAWATAP, CAMECA version) using UV $(343 \mathrm{~nm})$ femtosecond laser pulses (50 nJ, $350 \mathrm{fs})$. APT principle relies on field evaporation of surface atoms of a specimen and their chemical identification by time-of-flight mass spectrometry. ${ }^{18-20}$ Before an analysis, the specimen is prepared in the form of a sharp tip with a radius of curvature smaller than $50 \mathrm{~nm}$. Specimen preparation has been detailed by Thompson $e t$ al. in a previous paper. ${ }^{21}$ The tip is placed under high vacuum $\left(\approx 10^{-8} \mathrm{~Pa}\right)$, at low temperature $(80 \mathrm{~K})$, and submitted to a high positive voltage $\left(V_{0} \approx 3-15 \mathrm{kV}\right)$. Under these conditions, an intense electric field (inversely proportional to the radius) is created at the tip apex (several V. $\mathrm{nm}^{-1}$ ). Surface atoms are ionized and evaporated by means of laser pulses. Then, ions are collected on a position sensitive detector. The time of flight of an ion (measured between the laser pulse and the impact on the detector) permits to identify its chemical nature by time of flight mass spectrometry. APT analysis has already been demonstrated to provide relevant and accurate results for similar materials. ${ }^{22,23}$

\section{RESULTS AND DISCUSSION}

\section{A. Reference sample}

The 3D reconstruction obtained on the reference sample is presented in Figure 1. Aforementioned, this sample was annealed for $1 \mathrm{~h}$ at $900^{\circ} \mathrm{C}$. Figures 1(a) and 1(b) represent silicon and oxygen atom position maps, respectively. In such APT reconstruction, each red dot corresponds to a single silicon atom while each green dot corresponds to an oxygen atom. Silicon supersaturation and oxygen depletion allow the identification of $\mathrm{SiO}_{X}$ and $\mathrm{SiO}_{2}$ sublayers in the stacking sequence of the ML and the composition of each sublayer can be measured by counting $\mathrm{Si}$ and $\mathrm{O}$ atoms. $\mathrm{SiO}_{2}$ sublayers composition has been measured to be $34.3 \pm 0.3$ at. \% of $\mathrm{Si}$, which corresponds to the composition of a pure silica layer $\left(X_{\mathrm{Si}}=33.3\right.$ at. \%). $\mathrm{SiO}_{X}$ sublayers contain $51.0 \pm 0.3$ at. $\%$ of $\mathrm{Si}$.

Since each sublayer has been clearly identified, it is possible to focus our investigation on $\mathrm{SiO}_{X}$ sublayers in which the phase separation and the particle growth occur. Si-nps are evidenced using a cluster identification algorithm. The principle of this algorithm is to place a sphere over each

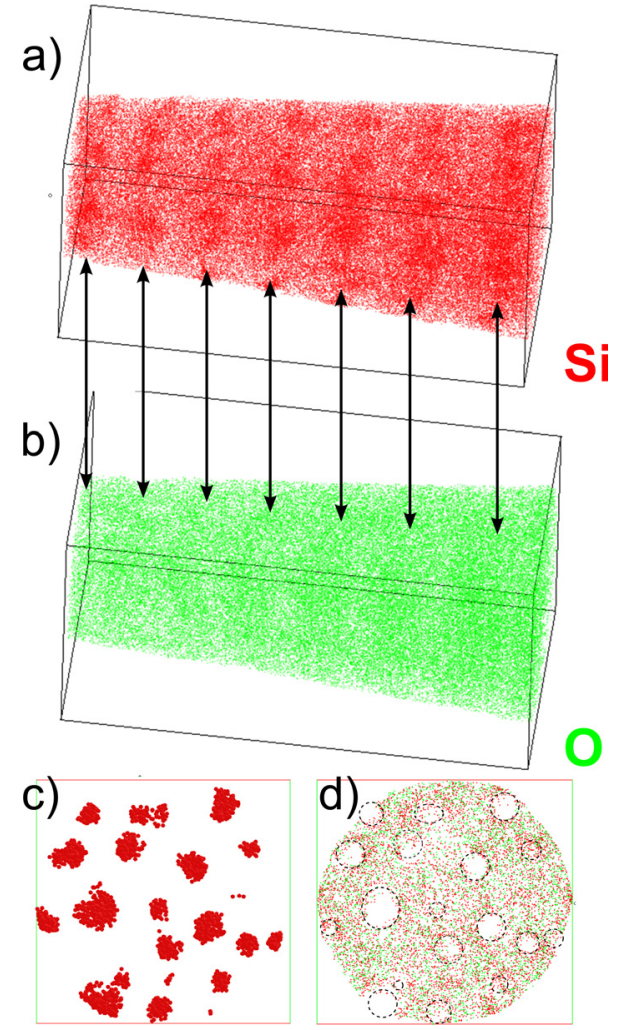

FIG. 1. 3D reconstruction of $\mathrm{SiO}_{X} / \mathrm{SiO}_{2}$ MLs annealed at $900^{\circ} \mathrm{C}$ during $1 \mathrm{~h}$. Arrows indicate $\mathrm{SiO}_{X}$ sublayers; (volume: $22 \times 22 \times 55 \mathrm{~nm}^{3}$ ). (a) Silicon mapping; (b) oxygen mapping; (c) single $\mathrm{SiO}_{X}$ sublayer. Silicon atoms belonging to Si-nps are evidenced with bold dots (volume: $20 \times 20 \times 4$ $\mathrm{nm}^{3}$ ); (d) suboxide matrix in this layer where Si-nps position is highlight by dashed-circle.

atom of the analyzed volume, then, the composition is measured in this sphere and compared to a threshold. If the composition is higher than this threshold, then the selected atom belongs to a cluster. If the composition is lower than this threshold, then the selected atom belongs to the matrix. The radius of the sphere $(1 \mathrm{~nm})$ and the concentration threshold (55\% at. of silicon) have been tuned in order to identify clearly every Si-np in analyzed volumes without missing atoms from the Si-nps. During the cluster identification algorithm, silicon and oxygen atoms from the matrix are inevitably selected as belonging to Si-nps because of local magnification effects, which can lead to trajectory aberration in such material. Corrections are applied to the measured composition and to the estimated number of atoms inside each cluster, as explained in Ref. 22. After this data treatment, it is possible to differentiate a silicon atom which belongs to a nanoparticle from an atom which belongs to the surrounding silicon oxide. From this moment, two different phases are defined inside $\mathrm{SiO}_{X}$ sublayers: the Si-nps and the surrounding matrix. Figure 1(c) shows the chemical mapping of a single $\mathrm{SiO}_{X}$ sublayer in which only $\mathrm{Si}$-nps are represented. In this configuration, chemical and structural properties of Si-nps, such as composition, size, and density, can be measured. The size of a single nanoparticle is determined by counting the number of $\mathrm{Si}$ atoms constituting the Si-np. Assuming a spherical shape the particle diameter is calculated using the following relation: 


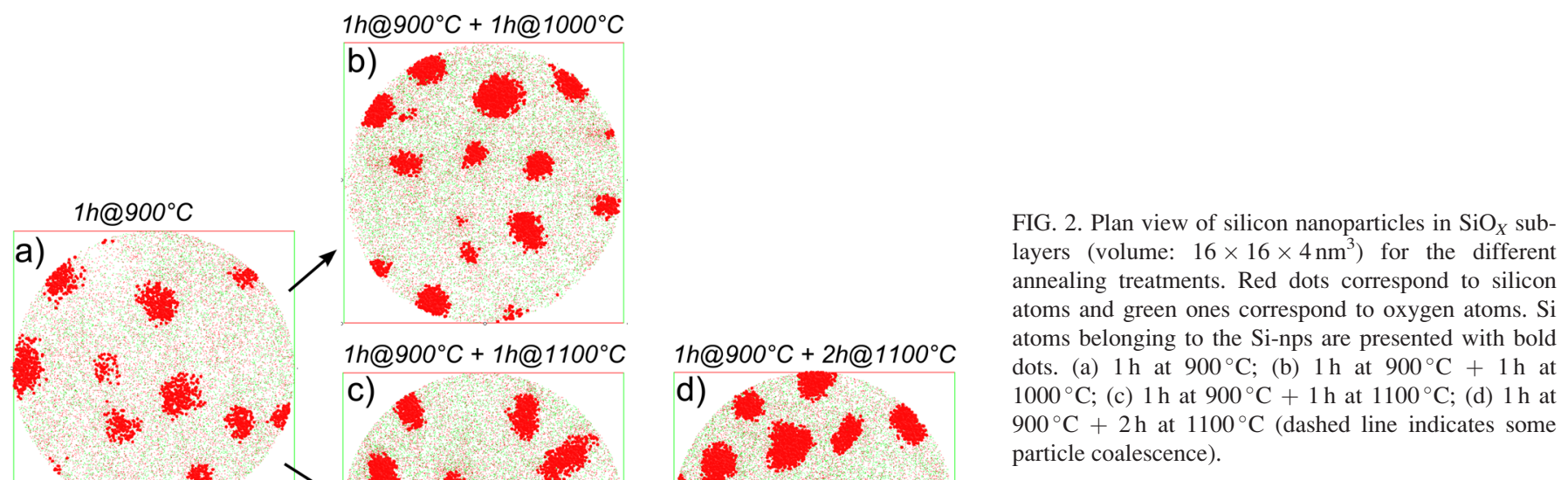
number of $\mathrm{Si}$ atoms in the particle, and $V_{\mathrm{Si}}$ is the atomic volume of a Si atom $\left(\mathrm{in} \mathrm{nm}^{3}\right)$. In this sample, the mean diameter of Si-nps is estimated to be $2.9 \mathrm{~nm}$, which is smaller than the thickness of $\mathrm{SiO}_{X}$ sublayers $(4 \mathrm{~nm})$. Figure 1(d) shows the chemical map of matrix atoms $\left(\mathrm{Si}\right.$ and $\mathrm{O}$ ) of a single $\mathrm{SiO}_{X}$ layer. The matrix contains $41.9 \pm 0.3$ at. $\%$ of Si distributed homogeneously. This concentration is significantly higher than in pure silica, which indicates that phase separation is not complete for this annealing treatment. Both measurements of mean radius and matrix composition indicate that further growth is achievable in $\mathrm{SiO}_{X}$ sublayers of the reference sample. In order to analyse the phase separation process, reference sample (a) $\left(1 \mathrm{~h}\right.$ at $\left.900^{\circ} \mathrm{C}\right)$ was cut in three parts, each part submitted to an additional annealing treatment: $+1 \mathrm{~h}$ at $1000^{\circ} \mathrm{C}$ (sample (b)); $+1 \mathrm{~h}$ at $1100^{\circ} \mathrm{C}$ (sample (c)); $+2 \mathrm{~h}$ at $1100^{\circ} \mathrm{C}$ (sample (d)). These results are described in Sec. III B.

\section{B. Additional annealing treatments}

Results obtained by APT after each annealing treatment (reference state and three additional annealing treatments) are represented in Figure 2. For each analysis, the atomic mapping of a single $\mathrm{SiO}_{X}$ sublayer is presented. In order to compare each nanostructure, identical volumes are represented and undergo the same data treatment (cluster identification algorithm, calculation of Si-np sizes, and measurement of matrix composition). It is important to note that Si-nps are exclusively observed into Si-rich sublayer for each annealing treatment. This confirms that $4 \mathrm{~nm}-\mathrm{SiO}_{2}$ acts as a strong diffusion barrier for silicon atoms. $\mathrm{SiO}_{X}$ sublayer images show that the average Si-np size increases with annealing time and temperature.

Si-np size distribution is calculated for the four annealing treatments and is reported in Figure 3(a) along with Sinp mean diameter. In the case of the reference state, most of

the nanoparticles $(55.2 \%)$ have a diameter, which range from $3 \mathrm{~nm}$ to $4 \mathrm{~nm}$; however, many nanoparticles $(39.6 \%)$ are smaller than $3 \mathrm{~nm}$. APT is capable of detecting Si-nps smaller than $1 \mathrm{~nm}$. Additional annealing treatment induces further Si-np growth, as evidenced by a size distribution
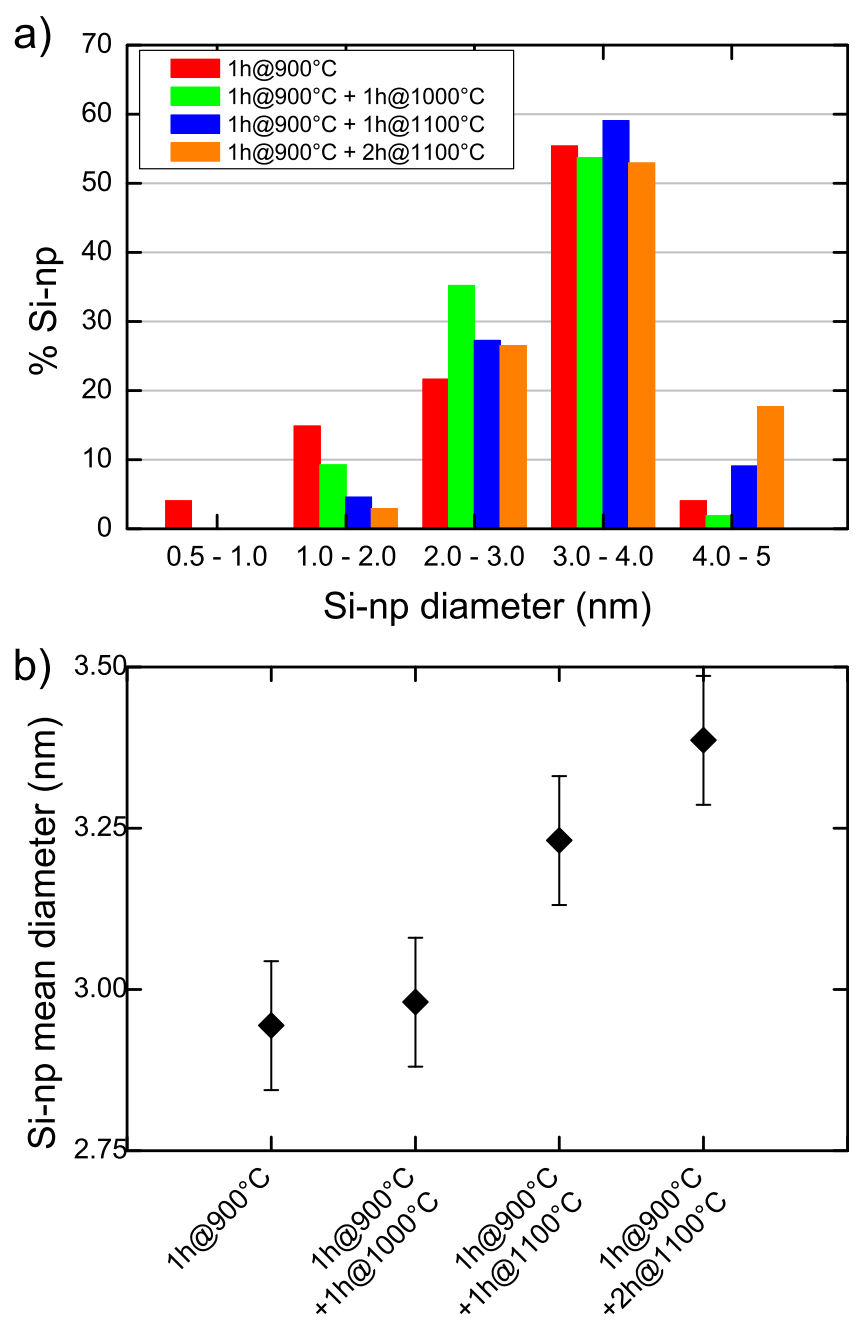

FIG. 3. (a) Si-np size distributions measured for reference state and three additional heat treatments; (b) mean diameter for each annealing treatment. 
shifting towards higher diameter values. Si-nps smaller than $1 \mathrm{~nm}$ were not observed after one additional hour of annealing at $1000{ }^{\circ} \mathrm{C}$ or higher. The number of nanoparticles inside the $1-2 \mathrm{~nm}$ range continuously decreases from $15 \%$ in the case of annealing treatment (a), to $3 \%$ in the case of annealing treatment (d). Concerning the last annealing treatment (d) the diameter of some nanoparticles appears to be larger than the thickness of the $\mathrm{SiO}_{X}$ sublayer. These nanoparticles can be located within analyzed volumes and correspond to coalescing nanoparticles as shown previously in Figure 2(d). Si-np mean diameter continuously increases with annealing time from $2.9 \mathrm{~nm}$ up to $3.4 \mathrm{~nm}$, as shown in Figure 3(b). This value is still lower than $\mathrm{SiO}_{X}$ sublayer thickness $(4 \mathrm{~nm})$, indicating that more Si-np could still grow. However, coalescence may lead to some changes in the morphology towards more elongated rather than spherical nanoparticles. In that case, APT would not be able to distinguish coagulated particles from single elongated particles.

Measuring the density of nanoparticle by counting the number of nanoparticles in each sublayer leads to a high uncertainty. This is due to the variability of the number of particles inside analyzed volumes, which are very small: \pm 1 particle in $20 \times 20 \times 4 \mathrm{~nm}^{3}$ typically. In order to avoid such an uncertainty, we have calculated the density of Si-nps $\left(\mathrm{N}_{S i-n p s}\right)$ in $\mathrm{SiO}_{X}$ sublayers using

$$
N_{\mathrm{Si}-\mathrm{nps}}=\frac{\Delta N_{\mathrm{Si}}^{\mathrm{ex}}}{n_{\mathrm{Si}}^{\text {particles }}},
$$

where $n_{\mathrm{Si}}^{\text {particles }}$ is the mean number of Si atoms belonging to a nanoparticle (deduced from the size distribution). This value is compared to the total amount of excess silicon atoms precipitated in the form of Si-nps $\left(\Delta N_{\mathrm{Si}}^{\mathrm{ex}}\right.$ in at $\left./ \mathrm{cm}^{3}\right)$. Calculated Si-np density is plotted as a function of annealing treatment in Figure 4(a). For the reference sample (a), the density of nanoparticles is estimated to be $11 \pm 1 \times 10^{18} \mathrm{Si}-\mathrm{np} / \mathrm{cm}^{3}$. The expected value assuming a complete phase separation (pure silica matrix and $4 \mathrm{~nm} \mathrm{Si-nps)} \mathrm{is} 9.9 \times 10^{18} \mathrm{Si}-\mathrm{np} / \mathrm{cm}^{3}$. The first additional annealing treatment increases the density of nanoparticles up to $22 \pm 1 \times 10^{18} \mathrm{Si}$-np $/ \mathrm{cm}^{3}$. Further annealing induces a lower density $17 \pm 1 \times 10^{18} \mathrm{Si}-\mathrm{np} / \mathrm{cm}^{3}$ and $15 \pm 1 \times 10^{18} \mathrm{Si}-\mathrm{np} / \mathrm{cm}^{3}$ for (c) and (d), respectively. Along with the evolution of the density, Si concentration in the matrix is also represented as a function of annealing treatment in Figure 4(b). Initial and final silicon concentrations have been represented for each annealing treatment in order to estimate how much silicon excess has precipitated during annealing. In the case of the first annealing treatment (a), silicon concentration decreases from 51 at. $\%$ to 42 at. $\%$. In the case of additional annealing treatments (b) and (c), silicon concentration starts from 42 at. $\%$ and reaches its equilibrium value (pure silica 33.3 at. \%). Finally, it is important to note that for annealing treatment (d), the matrix initial composition is already the equilibrium value of silica: 33.3 at. $\%$.

Key structural and chemical parameters of the samples presented in this section are summarized in Table I. For each annealing treatment, it gives initial and final mean radius,
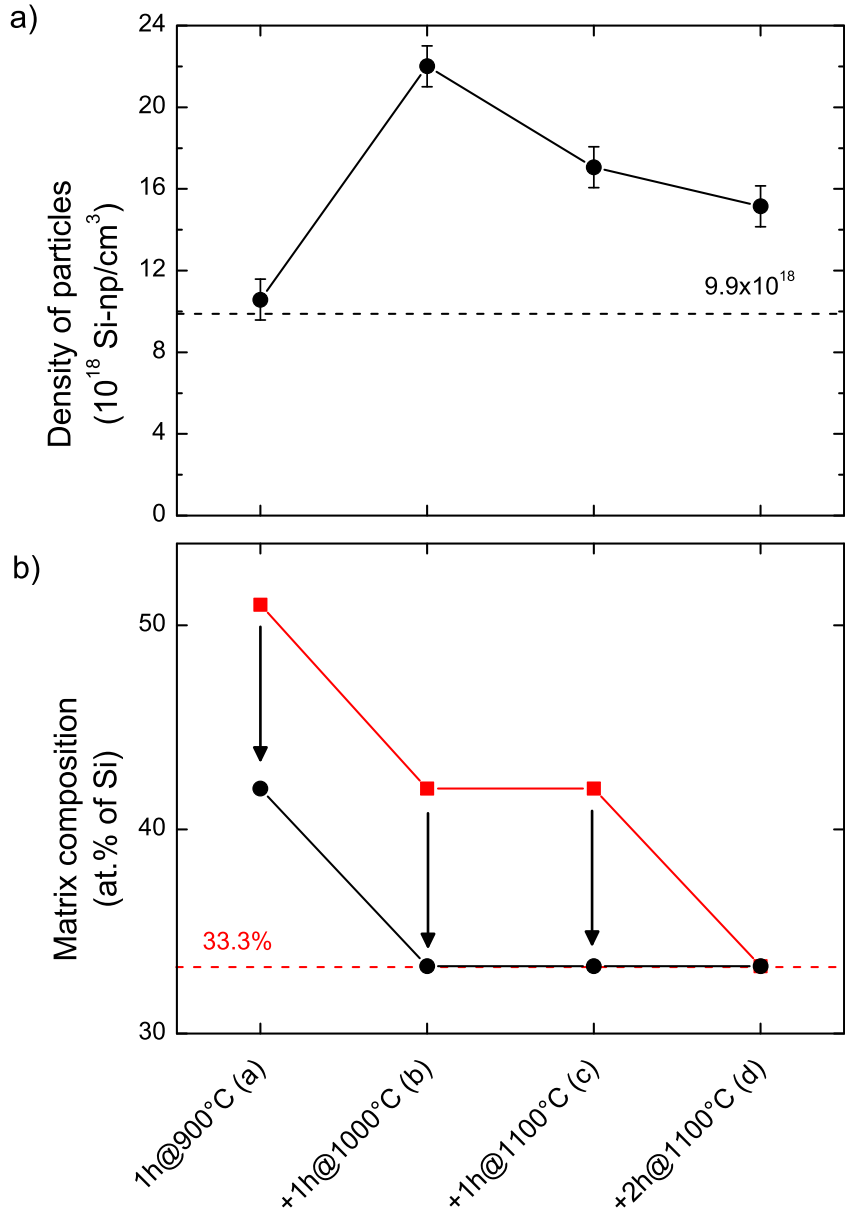

FIG. 4. (a) Density of particles in $\mathrm{SiO}_{X}$ sublayers for each annealing treatment. (b) Initial and final matrix supersaturation for each annealing treatment. Dashed lines represent expected density value (a) and matrix composition (b) in a theoretical layer in which all $\mathrm{Si}$ excess has precipitated in the form of precipitates with a diameter of $4 \mathrm{~nm}$. Solid lines connecting the experimental points are drawn to guide the eye only.

initial and final matrix concentration, as well as initial and final density of nanoparticles.

\section{Apparent diffusion coefficient}

As highlighted by Tsoukalas et al., ${ }^{14} \mathrm{Si}$ diffusion coefficient $\left(D_{\mathrm{Si}}\right)$ measurements appear to be highly dependent on experimental approach and especially on silicon concentration in silicon oxide. For instance, $D_{\mathrm{Si}}$ appears to be higher in silicon-implanted silica $^{14}$ or grown silicon-rich silica ${ }^{16}$

TABLE I. Structural and chemical characteristics of analyzed multilayers. For each annealing treatment, initial and final radius of Si-nps (calculated from Eq. (1)), initial and final matrix composition, and initial and final number density of nanoparticles are given.

\begin{tabular}{|c|c|c|c|c|c|c|}
\hline $\begin{array}{l}\text { Annealing } \\
\text { treatment }\end{array}$ & $\begin{array}{c}R_{1} \\
(\mathrm{~nm})\end{array}$ & $\begin{array}{c}R_{2} \\
(\mathrm{~nm})\end{array}$ & $\begin{array}{c}\text { Initial matrix } \\
\text { composition } \\
X_{\mathrm{SiO}_{\mathrm{x}}} \\
\text { (at. \%) }\end{array}$ & $\begin{array}{c}\text { Final matrix } \\
\text { composition } \\
X_{\mathrm{SiO}_{\mathrm{x}}} \\
\text { (at. \%) }\end{array}$ & $\begin{array}{c}\text { Initial } \\
\text { density } \\
\left(10^{18}\right. \\
\left.\text { Si-np/cm } \mathrm{cm}^{3}\right)\end{array}$ & $\begin{array}{c}\text { Final } \\
\text { density }\end{array}$ \\
\hline (a) & 0 & 1.47 & $51 \%$ & $42 \%$ & 0 & 11 \\
\hline (b) & 1.47 & 1.49 & $42 \%$ & $33.3 \%$ & 11 & 22 \\
\hline (c) & 1.47 & 1.62 & $42 \%$ & $33.3 \%$ & 11 & 17 \\
\hline (d) & 1.62 & 1.69 & $33.3 \%$ & $33.3 \%$ & 17 & 15 \\
\hline
\end{tabular}


than in stoichiometric silica. ${ }^{15,17}$ The growth of Si-nps is related to an apparent diffusion coefficient. Hence, we used the data collected in the previous section in order to estimate this coefficient. Previous publications propose several mechanisms for the formation of Si-nps: diffusion controlled growth, ${ }^{16,24}$ Ostwald ripening, ${ }^{25}$ and more complex processes such as oxygen out-diffusion from precipitates. ${ }^{26}$ In the present study, both diffusion controlled growth and Ostwald ripening have been considered, depending on the supersaturation and the growing sequence: growth followed by coarsening. Drawing inspiration from Nesbit, ${ }^{16}$ a classical growth approach is used to relate the apparent silicon diffusion coefficient $D_{\mathrm{Si}}$ to Si-np mean radius. This model assumes that $\mathrm{Si}-$ $\mathrm{np}$ growth is related to the consumption of $\mathrm{Si}$ excess atoms from the surrounding matrix. Thus, it can only be used in supersaturated silica. $D_{\mathrm{Si}}$ can be deduced from a simple application of the classical growth equation

$$
D_{\mathrm{Si}}=\frac{R_{2}^{2}-R_{1}^{2}}{2\left(t_{2}-t_{1}\right)} \frac{X_{\mathrm{Si}}-X_{\mathrm{SiO}_{2}}}{X_{\mathrm{SiO}_{\mathrm{X}}}-X_{\mathrm{SiO}_{2}}},
$$

where $\left(t_{2}-t_{1}\right)$ represents the annealing time, $R_{1}$ and $R_{2}$ are Si-np mean radius before and after annealing, respectively.

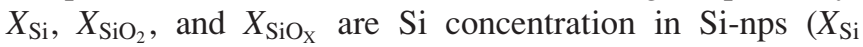
$=1.00)$, Si concentration in pure $\mathrm{SiO}_{2}\left(X_{\mathrm{SiO}_{2}}=0.33\right)$, and $\mathrm{Si}$ concentration in $\mathrm{SiO}_{X}\left(X_{\mathrm{SiO}_{\mathrm{x}}}=1 /(1+x)\right)$, respectively.

In the case of a very low supersaturation, LSW theory (or Ostwald ripening) ${ }^{27,28}$ predicts that Si-np growth is related to the coarsening of nanoparticles. ${ }^{25}$ In this model, silicon atoms coming from dissolving small nanoparticles diffuse towards bigger nanoparticles through the unsaturated matrix. In that process, the diffusion coefficient $D_{\mathrm{Si}}$ can be extracted as

$$
D_{\mathrm{Si}}=\frac{9 R_{g} T}{8 \gamma X_{\mathrm{SiO}_{2}} V_{m}} \frac{\left(R_{2}^{3}-R_{1}^{3}\right)\left(X_{\mathrm{Si}}-X_{\mathrm{Si}_{2}}\right)}{\left(t_{2}-t_{1}\right)},
$$

where $R_{g}$ stands for the universal gas constant $\left(R_{g}=8.31\right.$ $\left.\mathrm{J} \cdot \mathrm{K}^{-1} \cdot \mathrm{mol}^{-1}\right), T$ stands for the annealing temperature, $\gamma$ stands for the interfacial energy, and $V_{m}$ stands for the volume of 1 mole of $\mathrm{Si}\left(V_{m}=12 \mathrm{~cm}^{3}\right) . \gamma$, which corresponds to the interfacial energy of a Si-np into $\mathrm{SiO}_{2}$, has been estimated to be about $\gamma \approx 1 \mathrm{~J} \cdot \mathrm{m}^{-2} \cdot{ }^{29}$

Thanks to the nanostructure characterization and the composition measurements carried out in the previous section, the growth mechanism of Si-nps is identified for each annealing treatment. Since high silicon composition is detected before annealing (a), (b), and (c), we considered a diffusion controlled growth mechanism in these cases. Thus, for (a), (b), and (c), Eq. (3) has been used in order to calculate $D_{\mathrm{Si}}$.

The density increases from sample (a) to samples (b) and (c). This indicates that nucleation still takes place in these samples. An overlap between nucleation and growth should be taken into account, as explained in Ref. 30. However, once a nucleus overcomes its critical radius, it is relevant to consider that its growth is diffusion controlled. The critical radius $r^{*}$ of a nucleus is given by
TABLE II. Calculated value of silicon diffusion coefficient for the different annealing treatment. For each annealing treatment, the temperature and the duration of the annealing, the initial and final radius of Si-nps, and the initial

\begin{tabular}{|c|c|c|c|c|c|c|}
\hline Treatment & $\begin{array}{c}\text { Temperature } \\
\left({ }^{\circ} \mathrm{C}\right)\end{array}$ & $\begin{array}{l}t_{2}-t_{1} \\
\text { (h) }\end{array}$ & $\begin{array}{c}R_{1} \\
\text { (in } \mathrm{nm} \text { ) }\end{array}$ & $\begin{array}{c}R_{2} \\
\text { (in } \mathrm{nm} \text { ) }\end{array}$ & $\begin{array}{l}\text { Initial matrix } \\
\text { composition } \\
X_{\mathrm{SiO}_{\mathrm{X}}} \text { (at. \%) }\end{array}$ & $\begin{array}{c}D_{\mathrm{Si}} \\
\left(\mathrm{cm}^{2} \cdot \mathrm{s}^{-1}\right)\end{array}$ \\
\hline (a) & 900 & 1 & 0 & 1.47 & $51 \%$ & $1.2 \times 10^{-17}$ \\
\hline (b) & 1000 & 1 & 1.47 & 1.49 & $42 \%$ & $5.6 \times 10^{-19}$ \\
\hline (c) & 1100 & 1 & 1.47 & 1.62 & $42 \%$ & $4.6 \times 10^{-18}$ \\
\hline (d) & 1100 & 1 & 1.62 & 1.69 & $33.3 \%$ & $3.8 \times 10^{-18}$ \\
\hline
\end{tabular}
matrix composition are given.

$$
r^{*}=\frac{-2 \gamma}{\Delta G_{\mathrm{V}}}
$$

where $\Delta G_{\mathrm{V}}$ is the driving force per volume unit and $\gamma$ is the interfacial energy. As predicted by the $\mathrm{Si}-\mathrm{O}$ phase diagram, ${ }^{12}$ Si solubility limit in $\mathrm{SiO}_{2}$ is extremely low $\left(\mathrm{SiO}_{2}\right.$ is a stoichiometric compound). The driving force for this transformation is close to infinity and the critical radius of a nuclei is close to zero. Hence, it is possible to relate particle growth to a diffusion controlled process, as mentioned by Nesbit. ${ }^{16}$

In the case of the last annealing treatment (d), initial supersaturation is extremely low (as mentioned previously, initial silicon concentration for this annealing treatment is $33.3 \%$, which correspond to pure silica). Thus, in that case, LSW theory and Eq. (4) have been used to calculate $D_{\mathrm{Si}}$. All the parameters required to calculate $D_{\mathrm{Si}}$ values are reported in Table II along with calculated diffusion coefficients.

Apparent silicon diffusion coefficients are represented as a function of inverse temperature and compared to previous results obtained by Tsoukalas et al., ${ }^{14}$ Nesbit, ${ }^{16}$ and Jaoul et al. ${ }^{17}$ in Figure 5. Differences between all these studies can be explained by the variation of silicon supersaturation in studied systems. In the system studied by Nesbit, silicon diffusion coefficient has been estimated using samples containing 55 at. $\%$ and 58 at. $\%$ of silicon. This

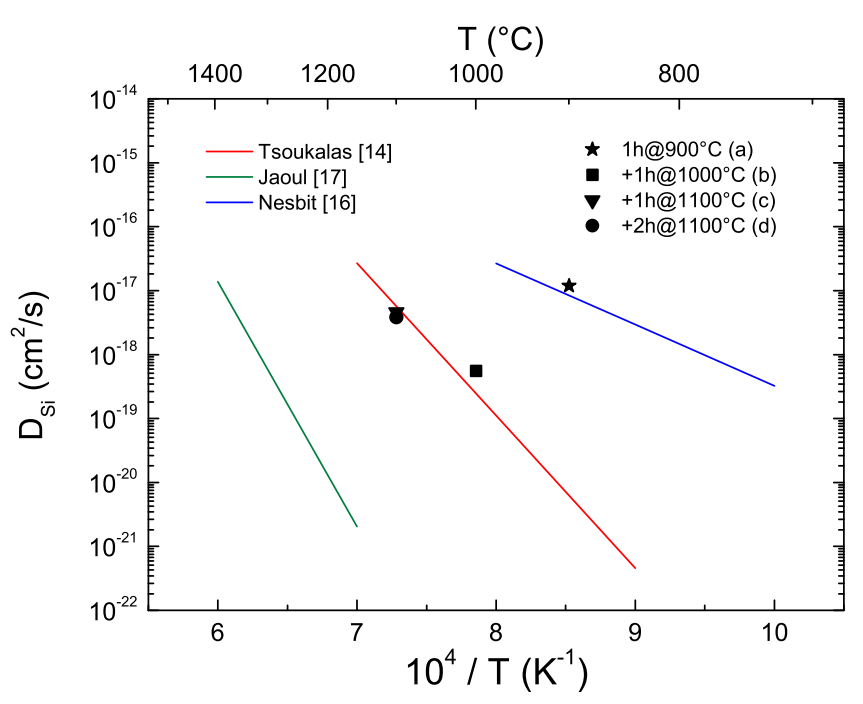

FIG. 5. Si diffusivity as a function of temperature in $\mathrm{SiO}_{X}$. Existing results referred in bibliography are illustrated with straight lines. Dots represent results obtained in the present study. 
TABLE III. Diffusion coefficient and mean free path of a silicon atom in $\mathrm{SiO}_{2}$ and $\mathrm{SiO}_{X}$ during $1 \mathrm{~h}$ as a function of annealing temperature.

\begin{tabular}{|c|c|c|c|c|c|c|}
\hline \multirow[b]{2}{*}{$\mathrm{T}\left({ }^{\circ} \mathrm{C}\right)$} & \multicolumn{3}{|c|}{$\mathrm{SiO}_{2}$ layers $\approx 33.3$ at. $\%$ of $\mathrm{Si}$ (from Tsoukalas et al.) } & \multicolumn{3}{|c|}{$\mathrm{SiO}_{X}$ layers $\approx 50.0$ at. $\%$ of $\mathrm{Si}$ (from Nesbit) } \\
\hline & 900 & 1000 & 1100 & 900 & 1000 & 1100 \\
\hline$D_{\mathrm{Si}}\left(\mathrm{cm}^{2} / \mathrm{s}^{-1}\right)$ & $6.19 \times 10^{-21}$ & $2.46 \times 10^{-19}$ & $5.70 \times 10^{-18}$ & $8.38 \times 10^{-18}$ & $3.66 \times 10^{-17}$ & $1.29 \times 10^{-16}$ \\
\hline$\langle d\rangle(\mathrm{nm})$ during $1 \mathrm{~h}$ & 0.07 & 0.42 & 2.03 & 2.46 & 5.14 & 9.64 \\
\hline
\end{tabular}

diffusion coefficient seems to be the highest. Tsoukalas et al. studied $\mathrm{SiO}_{2}$, which had been implanted with $\mathrm{Si}^{3} 0$ ions at $50 \mathrm{keV}$ to a dose of $2 \times 10^{-15} \mathrm{~cm}^{2}$. The implanted dose represents a much smaller silicon supersaturation (less than 0.1 at. $\%$ of excess silicon). The diffusion coefficient measured by Tsoukalas et al. is lower than the one estimated by Nesbit. As for Jaoul et al., they studied Si diffusion in pure quartz and measure the lowest diffusion coefficient. Thus, it seems that $D_{\mathrm{Si}}$ is higher in highly supersaturated silica. Our measurements of $D_{\mathrm{Si}}$ are coherent with this statement. In the case of annealing (a), where the $\mathrm{SiO}_{X}$ matrix initially contained 51 at. \% of silicon, we measure the highest value for $D_{\mathrm{Si}}$ (approximately the same as the one measured by Nesbit). In the case of annealing (b), (c), and (d), where the $\mathrm{SiO}_{X}$ matrix initially contains less Si excess (respectively, 42 at. \% and 33.3 at. $\%$ of silicon), we measure a lower value for $D_{\mathrm{Si}}$ (approximately the same as the one measured by Tsoukalas).

Our experimental results, obtained for different temperatures and for various silicon concentrations, clearly evidence the dependence of the apparent silicon diffusion coefficient with $\mathrm{Si}$ supersaturation in $\mathrm{SiO}_{X}$. The highest value of diffusivity is obtained for the highest supersaturation (case (a), which has been annealed $1 \mathrm{~h}$ at $900^{\circ} \mathrm{C}$ ). Diffusivity drastically decreases with supersaturation, as observed for annealing treatments (b), (c), and (d) (even if they have been annealed at higher temperatures). This dependence of silicon diffusion coefficient with the silicon supersaturation into $\mathrm{SiO}_{X}$ has been computationally predicted by Orlandini et al $^{31}$ and is attributed to a change in diffusion mechanisms. For low silicon supersaturations, diffusion is oxygen-driven, and this process is extremely slow. But for high silicon supersaturations, diffusion becomes silicon-driven and is much faster. Here we present experimental evidence that confirms this prediction. Moreover, the low coefficient diffusion in $\mathrm{SiO}_{2}$ is in good agreement with the fact that Si-nps are exclusively observed in Si-rich layers. This confirms $\mathrm{SiO}_{2}$ diffusion barriers efficiency.

\section{Silica diffusion barrier}

We demonstrated that $D_{\mathrm{Si}}$ varies with $\mathrm{SiO}_{X}$ sublayer composition. Thus, in $\mathrm{SiO}_{X} / \mathrm{SiO}_{2} \mathrm{MLs}$, there are two different regions with two different diffusion coefficients. In $\mathrm{SiO}_{X}$ sublayers, which initially contain more than $50 \%$ at. of silicon, we demonstrated that $D_{\mathrm{Si}}$ can be compared to the diffusion coefficient measured by Nesbit in $1985^{16}$

$$
D_{\mathrm{Si}}^{\mathrm{Nesbit}}=1.2 \times 10^{-13} \exp \left(\frac{-1.9 \times 1.6 \times 10^{-19}}{k_{\mathrm{B}} T}\right) .
$$

In $\mathrm{SiO}_{2}$ sublayers though, $D_{\mathrm{Si}}$ can be compared to the diffusion coefficient measured by Tsoukalas et al. ${ }^{14}$

$$
D_{\mathrm{Si}}^{\mathrm{Tsoukalas}}=1.378 \times 10^{-4} \exp \left(\frac{-4.74 \times 1.6 \times 10^{-19}}{k_{\mathrm{B}} T}\right) \text {. }
$$

From this equation, it is possible to estimate the mean free path $\langle d\rangle$ of a silicon atom through $\mathrm{SiO}_{X}$ or $\mathrm{SiO}_{2}$ layers along the stacking direction

$$
\langle d\rangle=\sqrt{2 \times(D t)} .
$$

$\langle d\rangle$ is calculated for $1 \mathrm{~h}$ annealing treatment, in the case of $\mathrm{SiO}_{X}$ and $\mathrm{SiO}_{2}$, and for different temperatures. They have been listed in Table III. These calculations permit to estimate the necessary thickness of $\mathrm{SiO}_{2}$ barriers, depending on the annealing treatment which is going to be applied. For instance, considering an annealing treatment of $1 \mathrm{~h}$ at $1000{ }^{\circ} \mathrm{C}, 0.42 \mathrm{~nm}$ thick $\mathrm{SiO}_{2}$ barriers will be necessary to prevent silicon to diffuse from one $\mathrm{SiO}_{X}$ layer to one other. Considering an annealing treatment of $1 \mathrm{~h}$ at $1100^{\circ} \mathrm{C}$ though, $2.03 \mathrm{~nm}$ thick barriers will be required.

In order to check the reliability of our model, we prepared two sets of $\mathrm{SiO}_{X} / \mathrm{SiO}_{2}$ multilayers. In both sets, $\mathrm{SiO}_{X}$ sublayer thickness and composition are the same $\left(\mathrm{SiO}_{X}\right.$ thickness is $4 \mathrm{~nm}$ and the layer contains $\approx 50$ at. \%. of $\mathrm{Si}$ ). The only changing parameter is $\mathrm{SiO}_{2}$ barrier thickness. This thickness is equal to $3.0 \mathrm{~nm}$ in the first sample set and to $1.5 \mathrm{~nm}$ in the second one. Each set of multilayers has been annealed for $1 \mathrm{~h}$ at $1000^{\circ} \mathrm{C}$ and for $1 \mathrm{~h}$ at $1100^{\circ} \mathrm{C}$. Figure 6 represents $3 \mathrm{D}$ reconstructions obtained by APT of these four samples. In each volume, red polygons represent isoconcentration surfaces set to 55 at. \% of $\mathrm{Si}$ and permit to evidence $\mathrm{Si}$-rich areas. As expected, $3 \mathrm{~nm}$ thick $\mathrm{SiO}_{2}$ barriers are sufficient to preserve the multilayered structure after $1 \mathrm{~h}$ at $100{ }^{\circ} \mathrm{C}$ (Figure 6(a)) and after $1 \mathrm{~h}$ at $1100^{\circ} \mathrm{C}$ (Figure 6(b)). This is consistent with our previous calculation. Concerning $1.5 \mathrm{~nm}$ thick $\mathrm{SiO}_{2}$ barriers, the multilayered structure is preserved after $1 \mathrm{~h}$ at $1000^{\circ} \mathrm{C}$ (Figure 6(c)). However, after $1 \mathrm{~h}$ at $1100{ }^{\circ} \mathrm{C}$, the $\mathrm{SiO}_{X} / \mathrm{SiO}_{2}$ stacking sequence has disappeared (Figure 6(d)). For this annealing treatment, we predicted a mean free path of $2.03 \mathrm{~nm}$. Since $\langle d\rangle$ is higher than $\mathrm{SiO}_{2}$ barrier thickness, $\mathrm{Si}$ atoms are able to diffuse from one $\mathrm{SiO}_{X}$ layer to one other and the multilayered structure is lost.

\section{CONCLUSION}

Silicon precipitation in supersaturated silica has been investigated by mean of APT. Several annealing treatments 

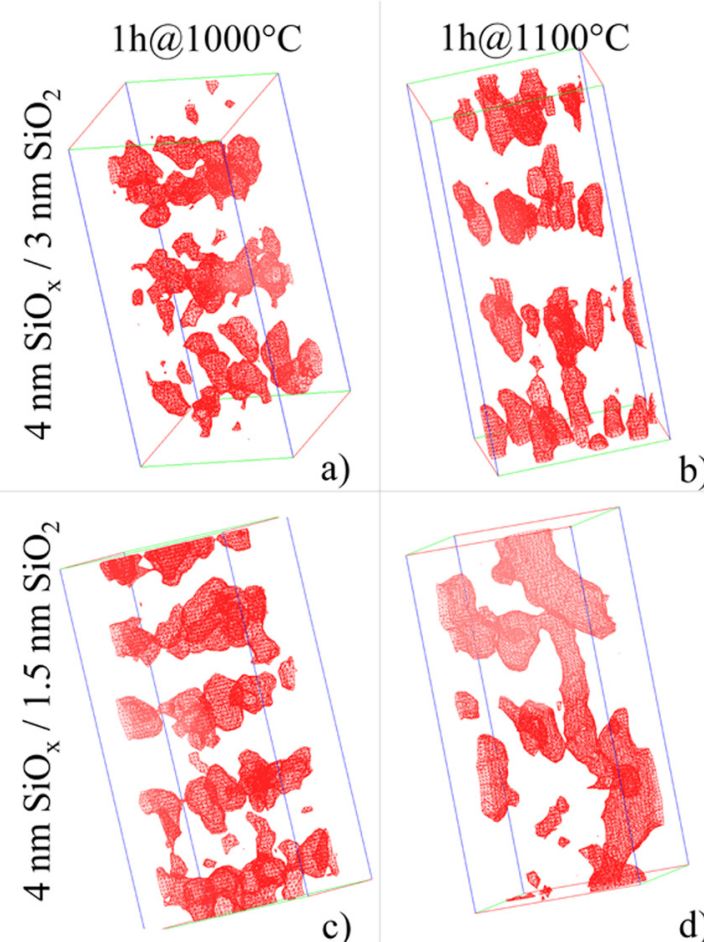

b)

c)

d)

FIG. 6. 3D reconstruction of two sets of sample with different $\mathrm{SiO}_{2}$ layer thicknesses and submitted to two different annealing treatments. (a) $3 \mathrm{~nm}$ thick $\mathrm{SiO}_{2}$ barriers, sample annealed for $1 \mathrm{~h}$ at $1000^{\circ} \mathrm{C}$. (b) $3 \mathrm{~nm}$ thick $\mathrm{SiO}_{2}$ barriers, sample annealed for $1 \mathrm{~h}$ at $1100^{\circ} \mathrm{C}$. (c) $1.5 \mathrm{~nm}$ thick $\mathrm{SiO}_{2}$ barriers, sample annealed for $1 \mathrm{~h}$ at $1000{ }^{\circ} \mathrm{C}$. (d) $1.5 \mathrm{~nm}$ thick $\mathrm{SiO}_{2}$ barriers, sample annealed for $1 \mathrm{~h}$ at $1100{ }^{\circ} \mathrm{C}$. In each volume, red polygons correspond to 55 at. \% of $\mathrm{Si}$ isoconcentration surfaces.

(ranging from $1 \mathrm{~h}$ at $900^{\circ} \mathrm{C}$ to $1 \mathrm{~h}$ at $900^{\circ} \mathrm{C}+2 \mathrm{~h}$ at $1100^{\circ} \mathrm{C}$ ) have been applied to $4 \mathrm{~nm}-\mathrm{SiO}_{X} / 4 \mathrm{~nm}-\mathrm{SiO}_{2}$ multilayered structures in order to induce $\mathrm{Si}$ precipitation. For each annealing treatment, changes in nanoparticle size, in nanoparticle density, and in matrix composition have been reported. By using diffusion controlled growth model and LSW theory, we have estimated an apparent silicon diffusion coefficients. These results lead to the conclusion that silicon supersaturation strongly influences the diffusion coefficient in $\mathrm{SiO}_{X}$ as predicted by Orlandini et al. These results can also explain the great variability in $D_{\mathrm{Si}}$ values reported in the literature and summed up by Tsoukalas et al. This phenomenon is already used in $\mathrm{SiO}_{X} / \mathrm{SiO}_{2}$ multilayers since $\mathrm{SiO}_{2}$ is commonly used as a diffusion barrier. We were able to calculate $D_{\mathrm{Si}}$ into silica and to predict the critical thickness for these diffusion barriers depending on the annealing time and temperature. Nevertheless, since $D_{\mathrm{Si}}$ decreases along with the silicon excess during the phase separation, a supersaturation-dependent diffusion coefficient should be taken into account in order to predict accurately the kinetics of $\mathrm{Si}-$ nps growth in $\mathrm{SiO}_{X}$ systems.

\section{ACKNOWLEDGMENTS}

This work was supported by the upper Normandy Research and the French Ministry of Research in the framework of Research Networks of Upper-Normandy. The authors also acknowledge "Le Fond Européen de Développement Régional” (FEDER) for its support.

${ }^{1}$ L. Canham, Appl. Phys. Lett. 57, 1046 (1990).

${ }^{2}$ F. Gourbilleau, C. Ternon, D. Maestre, O. Palais, and C. Dufour, J. Appl. Phys. 106, 013501 (2009).

${ }^{3}$ M. Fujii, M. Yoshida, Y. Kanzawa, S. Hayashi, and K. Yamamoto, Appl. Phys. Lett. 71, 1198 (1997)

${ }^{4}$ S. Tiwari, F. Rana, H. Hanafi, A. Harstein, E. Crabbe, and K. Chan, Appl. Phys. Lett. 68, 1377 (1996).

${ }^{5}$ T. Creazzo, B. Redding, E. Marchena, J. Murakowski, and D. Prather, J. Lumin. 130, 631 (2010)

${ }^{6}$ N. Daldosso, M. Luppi, S. Ossicini, E. Degoli, R. Magri, G. Dalba, P. Fornasini, R. Grisenti, F. Rocca, L. Pavesi, S. Boninelli, F. Priolo, C. Spinella, and F. Iacona, Phys. Rev. B 68, 085327 (2003).

${ }^{7}$ A. Romanyuk, V. Melnik, Y. Olikh, J. Biskupec, U. Kaiser, M. Feneberg, K. Thonke, and P. Oelhafen, J. Lumin. 130, 87 (2010).

${ }^{8}$ S. Schamm, C. Bonafos, H. Coffin, N. Cherkashin, M. Carrada, G. Ben Assayag, A. Claverie, M. Tencé, and C. Colliex, Ultramicroscopy 108, 346 (2008).

${ }^{9}$ P. Normand, E. Kapetanakis, P. Dimitrakis, D. Tsoukalas, K. Beltsios, N. Cherkashin, C. Bonafos, G. Benassayag, H. Coffin, A. Claverie, V. Soncini, A. Agarwal, and M. Ameen, Appl. Phys. Lett. 83, 168 (2003).

${ }^{10}$ T. Baron, F. Mazen, C. Busseret, A. Souifi, P. Mur, F. Fournel, M. N. Smria, H. Moriceau, B. Aspard, P. Gentile, and N. Magnea, Microelectron. Eng. 61-62, 511 (2002).

${ }^{11}$ S. Guha, M. Pace, D. Dunn, and I. Singer, Appl. Phys. Lett. 70, 1207 (1997).

${ }^{12}$ S.M. Schnurre, J. Grobner, and R. Schmid-Fetzer, J. Non-Cryst. Solids 336, 1 (2004)

${ }^{13}$ C. Ternon, F. Gourbilleau, X. Portier, P. Voidevel, and C. Dufour, Thin Solid Films 419, 5 (2002).

${ }^{14}$ D. Tsoukalas, C. Tsamis, and P. Normand, Mater. Res. Soc. Symp. Proc. 669, J3.7.1 (2001).

${ }^{15}$ G. Brebec, R. Seguin, C. Sella, J. Bevenot, and J. C. Martin, Acta Metall. 28, 327 (1980).

${ }^{16}$ L. A. Nesbit, Appl. Phys. Lett. 46, 38 (1985).

${ }^{17}$ O. Jaoul, F. Bejina, F. Elie, and F. Abel, Phys. Rev. Lett. 74, 2038 (1995).

${ }^{18}$ E. Muller, J. Panitz, and S. McLane, Rev. Sci. Instrum. 39, 83 (1968).

${ }^{19}$ D. Blavette, B. Deconihout, A. Bostel, J. M. Sarrau, M. Bouet, and A. Menand, Rev. Sci. Instrum. 64, 2911 (1993).

${ }^{20}$ G. Gault, F. Vurpillot, A. Vella, M. Gilbert, A. Menand, D. Blavette, and B. Deconihout, Rev. Sci. Instrum. 77, 043705 (2006).

${ }^{21}$ K. Thompson, D. Lawrence, D. J. Larson, J. D. Olson, T. F. Kelly, and B. Gorman, Ultramicroscopy 107, 131 (2007).

${ }^{22}$ E. Talbot, R. Larde, F. Gourbilleau, C. Dufour, and P. Pareige, Europhys. Lett. 87, 26004 (2009).

${ }^{23}$ E. Talbot, M. Roussel, C. Genevois, P. Pareige, L. Khomenkova, X. Portier, and F. Gourbilleau, J. Appl. Phys. 111, 103519 (2012).

${ }^{24}$ F. Iacona, C. Bongiorno, C. Spinella, S. Boninelli, and F. Priolo, J. Appl. Phys. 95, 3723 (2004).

${ }^{25}$ C. Bonafos, B. Colombeau, M. Carrada, A. Altibelli, and A. Claverie, Mater. Sci. Eng. B 88, 112 (2002).

${ }^{26}$ A. Sarikova, V. Litovchenko, I. Lisovskyy, I. Maidanchuk, and S. Zlobin, Appl. Phys. Lett. 91, 133109 (2007).

${ }^{27}$ I. M. Lifshitz and V. V. Slyozov, J. Phys. Chem. Solids 19, 35 (1961)

${ }^{28}$ C. Wagner, Z. Elektrochem. 65, 581 (1961).

${ }^{29}$ F. Djurabekova and K. Nordlund, Phys. Rev. B 77, 115325 (2008).

${ }^{30}$ J. D. Robson, Acta Mater. 52, 4669 (2004).

${ }^{31}$ S. Orlandini, S. Meloni, M. Ippolito, and L. Colombos, Phys. Rev. B 81, 014203 (2010). 